\title{
The impact of organizational justice on organizational commitment and creative behaviour among thermal power Industrial employees
}

\author{
Neha Kumari ${ }^{1}$, Nishat Afroz ${ }^{2}$ \\ Department of Psychology, Banaras Hindu University, Varanasi, India
}

\begin{abstract}
The study of justice and fairness is becoming one of the most flourishing areas of empirical and conceptual research in organizational behaviour. Good organizational justice can lead to ideal and favourable outcomes in the workplace. It is expected that employees will act according to organizational rules and regulations if they are treating fairly and received the outcomes they desire. A commitment is a tendency which develops attachment to the organization of the employees. There are large numbers of studies have sought to link justice perceptions to a variety of organizational outcome like organizational commitment and creative behaviour. The purpose of this study is to analyse the impact of organizational justice as encompassed by three dimensions, namely distributive justice, procedural justice and interactional justice on employee's organizational commitment and creativity behaviour. The sample includes 70 employees of NTCP of India from Sonbhadra District. The sample consisted of managerial employees who volunteered to participate in the study. The data have been analysed by using descriptive analysis and correlation. The results of Pearson correlation indicated that organizational justice significantly related to commitment and creative behaviour among thermal power employees.
\end{abstract}

Keywords: organizational justice, organizational commitment, creative behaviour.

\section{Introduction}

Organizational justice has been among the most frequently researched topics in industrial organizational psychology, human resources management, and organizational behavior. Not surprisingly, social scientists have found themselves sufficiently intrigued by these matters to examine them in detail in recent year, the study of organizational justice one of the most popular foci of organizational scholars today. Employees play a substantive role in taking many decisions in organizations. Whether the decisions made with regards to the employees in the facilities are just is occasionally questioned. The behaviors of the employees against justice began to be analyzed, as justice being taken seriously in facilities. Justice research might be better served by focusing on perceptions of fairness. There are large numbers of studies have sought to link justice perceptions to a variety of organizational outcome like organizational commitment and creative behaviour.Organizational justice is an important issue in organizational behaviour because it has been joined to decisive organizational processes like commitment and creativity behaviour, job satisfaction, OCB, trust. Justice defined a broad in applied researches and theoretical studies in organizational settings. Greenberg (1990)[16] defined justice as employees' perceptions of workplace fairness connected to managerial behavior. Many findings has been demonstrated that workplace fairness is most important component and that employee perception of justice can effects organizational outcomes ( Cohen- Charash \& Spector, 2001; Cropanzano \& Greenberg, 1997; Greenberg, 2001; Jordan \& Turner, 2008)[11]. Organizational justice is an evaluation process that connected to management decisions and encloses three dimensions, which composed of distributive, procedural, and interactive justice (Greenberg, 1987; Searle \& Ball, 2004)[16]. The distributive dimension of justice is related to a long-term relation in organizational operation (Moorman, Blakely \& Brian, 1998)[24] and focuses on the fairness of the allocation of outcome decisions (Searle \& Ball, 2004) or rewards received for effort, e.g. promotions, incentives, merit and salary increases. Procedural justice, as a term used to describe the role of fairness in the organization, which refers to employees' perceptions of the fairness of procedures used to effects those outcomes (Cropanzano \& Greenberg, 1997; Ngodo, 2008)[10]. The third dimension of justice is interactional justice; it refers to the treatment of others with respect to dignity (Werbel \& Henriques, 2009). It has been also an important predictor of outcomes as well as distributive and procedural justice. The employee feels satisfaction or dissatisfaction on the basis of organizational commitment. A commitment is a tendency which develops attachment to the organization of the employees. Many people faithfully commit themselves to activities such as institutions, political parties. Commitment is a feeling of attachment to the organization (Lambert, Barton, \& Hogan, 1999). Organizational commitment is a bond to the whole organization and not to the job, work group, or belief in the importance of work itself. There is an important relationship between the 
organization and the individual and the extent to which commitment to an organization promotes other positive work behaviors (Allen and Mayer, 1997)[19]. It describes three factors of organizational commitment

(1) a strong belief in an organization's goals and values,

(2) a willingness to exert considerable effort for the organization,

(3) a strong desire to maintain membership in the organization.

There are three dimensions of Organizational commitment, affective, continuance and normative commitment, characterising an employee's commitment to the organization, has been the dominant framework:

Affective commitment (AC) reflects as the employee's positive emotional attachment to, and an emotional sense of identification with the organization. An employee who has affective commitment to his/her workplace desires to remain part of the organization. Continuance commitment (CC) as an employee commitment based on the economic and social costs of leaving the organization. Continuance commitment chooses to stay with the organization because of a lack of a better alternative. Normative commitment (NC) is defined as sense of moral obligation to the organization. An employee who has normative commitment stays with the organization to reciprocate the benefits he/she receives

In today's world it is more important to be creative and innovative. That means thinking in new ways and being open to completely different ways of seeing the world. Creativity has been a grossly complex word. The word creativity change in performance gets misconstrued as creativity. It is distinct from invention. Invention is the process of developing and expressing novel ideas that are likely to be useful. Creativity is the embodiment of such idea or inventions into new products, processes or services. Creativity and innovation have a role to play in this change process for survival. Organizations are bringing creativity to life through innovative products and service that customer's desire, therefore fulfilling customer's need, creative jobs, and contributing to the economy, therefore, organizational creativity and innovation play an integral role in serving all of us. Researches on employee organizational justice have a relatively short history. Researches on this area are conducted in social psychology or justice originally comes out social psychology with Adam's equity theory. Many researchers have studied and found some specific core personal characteristics, related to creative performance and commitment of the employees in different domains such as interest intelligence, cognitive style, attitude, behaviour, attraction of complexity and many more. There are several studies related to organizational justice, organizational commitment and creative behaviour. The literature on organizational justice has been suggested that both distributive (equity) and procedural justice components may impact creative work behaviour. On the other hand, the psychological contract revels that employee's perspective; fulfilment of mutual contractual obligations (psychological contracts) may influence their creative workplace behaviours. Therefore, we integrated the literature on, organizational justice and psychological attachment to predict creative work behaviours. In the relationship between organizational commitment and employee creativity behaviour, (Mathieu and Zajac, 1990; Meyer, et al., 2002)[20] it was found that employees with high job satisfaction show the highest creativity when commitment was high, thus, employees with high connection show better integration between individual-level creativity and organization's goals, and highest capability to translate their commitment to the organization into creative performance to organizational development. Bakhshi \& kumar (2009) [8]was argued that the relationship between perceived organization justice, job satisfaction and organizational commitment, result was found that distributive justice was significantly with job satisfaction whereas procedural justice was not found to be related significantly with job satisfaction. Also both distributive and procedural justice was found to be significantly to organizational commitment. In Swails' (2000) study, the relationship between organizational commitment and employee creativity it was explored through both qualitative and quantitative methods. During the interviews with some supervisors in technology-based organizations, the interviewees all illustrated that a committed person in their organizations is someone who is looking to innovate, create, and satisfy customer needs and is looking for ways of improving the business operations - these belong to the most important aspects of meeting an organization's goal, especially in knowledge-intensive companies. The positive influence of organizational commitment on employee-level creativity was also found by (Cekmecelioglu and Gunduz 2006). Gupta, Sharma and Rahman (1991)[17] made a study on scientists and their commitment to organization's goals with the main operative variables as recognition, professional freedom and researcher supervision relationship. The study revealed that scientists with less experience, those with high recognition are highly committed; the freedom of scientists to select the field of research supervisor relationship shows an increment in the degree of commitment. Sinha (1997) in survey of Indian organizations found that percentage of studies on organizational commitment of managers to be one of the important issues facing organizations. Punekar and Haribabu (1998) noted that adequate study has not been done on value orientation and suggested that commitment is basically a value orientation of the individual or group and comprises of values namely 'performance value' and 'discipline value'.

In a study, Aggrawal and Verma (1997)[26] compare high creativity and low creativity employees were significantly more internal than the low-creative employees. In an Indian study, Jain, Jain, \& Dhar (2004)[27] compared managers working in different Indian public and private sectors; they found that managers 
with internal locus of control showed significantly higher managerial creativity in comparison to managers with external locus of control irrespective of public of private sector.

Angle (1999) first reviewed the literature to know, how justice related to creativity, and discussed highlighting the importance of information flows in it. Kimberly (1981) found that in relatively stable environments, some formulation and centralization of decision- making can lead to free up time for employees to focus on more creative/ innovative endeavors.

In a literature review conducted by Tesluk, Farr, and Klein (1997) focusing on how organizational culture and climate influenced commitment and creativity at the individual level, identified five dimensions of organizational climate that influence creativity, including goal emphasis, mean emphasis, reward orientation, task support, and socio emotional support. Einsteins and Hwang (2007) found four aspects of organizational culture that were associated with organizational creativity: A supportive environment, autonomy, job challenges and open communication. Organizational creativity is a function of the creative outputs of its component groups and contextual influences (organizational culture, reward systems, resource constraints, the larger environment outside the system, and so on). The creative output (new products, services, ideas, procedures, and processes) for the entire system stems from the complex of individual, group, and organizational characteristics and behaviors occurring within the salient situational influences (both creativity constraining and enhancing) existing at each level of social organization. One of the important researches that exist in the literature on creativity, performance, creativity, is the creativity from the perspective of field success factors. The successes and failures in industries in western were examined. The result was that success is a direct relationship with performance. After these pioneering studies, other researchers confirmed the importance of speed in creativity will field succeed. Creativity is one of the most important and most complex issues organizations faced with today. Creativity is the success key for organizations. Every company should has creative process from creation to playing, when a product enters growth step, the company must play a change in product for supplying to market, because, another companies have reached the technology for producing. Now in this paper, related studies exploring the relationship between predictor (organizational commitment and creative behavior) and criterion variable are organizational justice.

\section{Gaps In Literature}

In a light of available research literature it is clear that commitment and creative behavior have significant relation with organizational justice. Relatively this topic is new so forth; limited studies were conducted to assess different aspects of creativity in the organizations. In government organization provide higher level of security this psychological makeup of employee in Indian still valid. Despite an increasing number of studies on organizational commitment and innovation no unifying work is focused on the measurement of degree of different in organizational justice in a public sector organization in Indian context.

Some researches has turned to individual works with 'respect' to how they relate to various aspect of organizing with their employees organization like work related attitudes (such as job satisfaction, commitment, and innovation, reward expectancies). So in this study identify the individual levels difference in Indian context

\section{Objective}

1. The study of organizational justice, and its relationship on organizational commitment and creative behaviour among thermal power employees.

2. To examine the role of organizational justice on organizational commitment among thermal power employees.

3. To examine the impact of organizational justice on creative behaviour among thermal power employees

\section{HYPOTHESIS}

1. There would be positive relation between organizational justice (dimension-wise) and organizational commitment.

2. There would be positive correlation between organizational justice (dimension-wise) and creative behaviour.

3. There would be positive relation between organizational justice, organizational commitment and creative behaviour.

\section{Participants}

\section{Methods}

The present study will be conducted on employees on NTCP of India in sonbhadra. This study will be carried out with 70 employees. Participant's age ranged from $22-42$ year Mean=30.73 and $\mathrm{SD}=4.65$ ) all 70 were male participants. Participants work job tenure ranged from 1-8 years. (Mean 2.34 and $\mathrm{SD}=1.29$ ) and total work experience ranged 1-16 (Mean=5.45 and $\mathrm{SD}=3.10$ ) the sample consisted of managerial employees who volunteered to participate in the study. 


\section{MEASURES}

Organizational Justice Scale (OJS) The OJS developed by Collquitt (2001). Response options are delivered on a Likert scale with possible responses ranging from 1 (strongly disagree) to 5 (strongly agree), with higher scores indicating a higher level of perceived organizational justice. The reliability of OJQ is 0.94 .

Organizational commitment scale: This scale was developed by Allen and Mayer (1991). It consists 18 items related on 5 point scale. The reliability of this scale is 0.87 .

Creative behavior questionnaire: This scale developed by Mishra and Singh. It consisted 13 items related on five point rating scale. The reliability of this scale is .73 high score indicates high creativity in managers.

\section{Data Analysis}

In the study the data was analyzed by using SPSS 16.0 statistical package. Statistical procedures used in the study included descriptive analysis of means and stander deviations, Pearson's coefficients (Pearson's r).

\section{Results}

Present study compare the mean, SD of different levels of managers in NTPC thermal power organization, the result of correlation analysis of organizational justice with all the three dimensions i.e., procedural justice, distributive justice and interactional justice, organizational commitment, with all dimensions i.e., affective commitment, continuance commitment, and normative commitment and total creative behavior. Table shows the result of correlation analysis of organizational justice with all the dimensions, organizational commitment, and total creative behavior. Results indicate that procedural justice is significantly positively correlated with distributive $\left(\mathrm{r}=.797^{* *}, \mathrm{p}<0.01\right)$ and interactional justice $\left(\mathrm{r}=.862^{* *}, \mathrm{p}<0.01\right)$. It is positively correlated with total creativity behavior $(\mathrm{r}=.164)$. Results also indicates procedural justice is significant negative correlate with affective commitment $\left(\mathrm{r}=-.418^{* *}, \mathrm{p}<0.01\right)$, and continuance commitment $\left(\mathrm{r}=-.270^{* *}, \mathrm{p}<0.01\right)$. In distributive justice that interest in significantly negative correlation with affective $\left(\mathrm{r}=.423^{* *}, \mathrm{p}<0.01\right)$, continuance commitment $\left(\mathrm{r}=-.283^{* *}, \mathrm{p}<0.01\right)$ and normative commitment $(\mathrm{r}=-.010)$. Distributive justice is positive correlated with interactional justice and creative behavior at 0.01 levels. Similarly, interactional justice has significant negative correlation with three dimension of organizational commitment (affective, normative and continuance). It would be significantly positively correlated with creative behavior ( $r=.284^{*}, \mathrm{p}<0.05$ ).

The results of correlation analysis of organizational commitment and its all three dimension (affective, continuance and normative), it has been found that affective commitment is significantly positive correlated with continuance $\left(\mathrm{r}=.381^{* *}, \mathrm{p}<0.01\right)$, normative commitment $\left(\mathrm{r}=.590^{* *}, \mathrm{p}<0.01\right)$ and creative behavior $(\mathrm{r}=$ $\left..362^{* *}, \mathrm{p}<0.01\right)$. Similarly continuance commitment is significantly positive correlated with normative ( $\mathrm{r}=$ $\left..621^{* *}, \mathrm{p}<0.01\right)$ and creative behavior $(\mathrm{r}=.062)$ and normative commitment is also significantly positive correlation with total creative behavior $\left(\mathrm{r}=.405^{* *}, \mathrm{p}<0.01\right)$.

Finally results indicates that the employees focuses on the fairness of the allocation of outcome, decisions and they are moral obligation to the organization but they are not emotionally attach to the organization on the base of economic and social cost of leaving the organization. Therefore employee's perception of fairness is high but they not committed to their organization on the basis of workplace attitude, behavior, emotional, social cost and economic criteria. In creativity is affected by the interaction of personal and organizational factors. They also point out many individuals and group, and organizational factors that could interact to influence employee's creativity. It is also affected by one or more of a variety of factors, including attributes, conceptual skills, abilities, technologies, empowerment, or the process of experiences.

Table -2 showed the correlation among the variables.

\begin{tabular}{|l|l|l|l|l|l|l|l|l|}
\hline Variables & Mean & SD & DJ & IJ & AC & CC & NC & TCB \\
\hline $\begin{array}{l}\text { Procedural } \\
\text { justice }\end{array}$ & 27.44 & 1.97 & $.797^{* *}$ & $.862^{* *}$ & $-.418^{* *}$ & $-.270^{* *}$ & .105 & .164 \\
\hline $\begin{array}{l}\text { Distributive } \\
\text { justice }\end{array}$ & 16.04 & 1.43 & & $.710^{* *}$ & $-.423^{* *}$ & $-.283^{* *}$ & -.010 & .054 \\
\hline $\begin{array}{l}\text { Interactional } \\
\text { justice }\end{array}$ & 35.92 & 2.36 & & & $-.408^{* *}$ & $-.519^{* *}$ & -.006 & $.284^{*}$ \\
\hline $\begin{array}{l}\text { Affective } \\
\text { commitment }\end{array}$ & 24.40 & 1.19 & & & & $.381^{* *}$ & $.590^{* *}$ & $.362^{* *}$ \\
\hline $\begin{array}{l}\text { Continuance } \\
\text { commitment }\end{array}$ & 24.52 & 1.81 & & & & & $.621^{* *}$ & .062 \\
\hline $\begin{array}{l}\text { Normative } \\
\text { commitment }\end{array}$ & 23.74 & 1.94 & & & & & & $.405^{* *}$ \\
\hline
\end{tabular}

**. Correlation is significant at the 0.01 level (2-tailed)

*Correlation is significant at the 0.05 level (1- tailed) 


\section{Discussion}

The aim of the present study was to examine the role of organizational justice and its relationship on organizational commitment and creative behaviour of the employees. The data has been analysed in term of the mean standard deviation and coefficient of correlation. The whole objective of the present investigation was to study of organizational justice relationship between commitment and creative behaviour among insurance employees. Present study related to organizational justice and organizational commitment it stated that organizational justice is negative correlated with two dimension of commitment that is affective or continuance commitment because of attitudinal components. The most attitudinal component of organizational settings is affective or continence commitment. Allen and Mayer (2001) three commitments in the public sector, the organization of the distinct relationship of three components of organizational commitment on a valuable of knowledge for the management of public organization.

Several studies have examined the effects of organization justice on organizational commitment in the public sector. Present study has been shows that employee commitment depends on the organizational culture, the effectiveness of socialization practices and the organization meeting of the employees work expectations, which are related to psychological contracts between the organization and employees with a three dimensional construct of organizational commitment. Belfour et.al.(1996) found that participation in decision making, political penetration in management, quality of supervisor and the opportunity for advancement if they are treated unfairly than it direct effects on all three dimension of organizational commitment. Decotiis and Summer (1987) was argued that an employee's perception of fairness in organization may have indirect effect an commitment which are mediated through their initial influence on the dynamic process of organizational commitment.

The present investigation was to explore the positive relationship between organizational justice and creative behaviour. Results of correlation analysis reveal that almost all dimension of organizational justice is positively correlated with creativity. The present study was found that creativity can be described as both an outcome and a process. Specifically, in order to produce creative outcomes, individual need to first engage in certain processes that can help them to become potentially more creative. It is an interactive process, involving reflection and action, seeking feedback, if these industries may high in employees behaviour than employees become attributes, conceptual skills, or the process of experiences is also being high these components explore the creativity in organization settings. Colquitt et al. (2001) reported only modest relationships for procedural justice and creative performance.

\section{Conclusion}

On the basis of results of the present study, following conclusions may be drawn:

1. Organizational justice has been negatively affect the organizational commitment with all the dimensions (affective, continuance, and normative), because they are not emotionally attach to the organization on the base of economic and social cost of leaving the organization.

2. Organizational commitment is also influence the individual's workplace attitude and job behavior and also its cultural climates.

3. Organizational justice has been strongly affecting the creative behavior of the employees.

4. Finding of the study was indicated that individual-level creativity and organization's goals, and greater abilities to translate their justice to the organization into creative performance.

\section{References}

[1] Amabile. T. M. 1988. A model of creativity and innovation in organizations. In B. M. Staw \& L. L. Cummings (Eds.). Research in organizational behavior. vol. 10: 123-167. Greenwich.CT: JAI Press.

[2] Amabile. T. M. 1990. Within you, without you: The social psychology of creativity and beyond.In M. A. Runco \& R. S. Albert (Eds.). Theories of creativity: 61-91. Newbury Park.CA: Sage.

[3] Amabile. T. M.. Goldfarb. P.. \& Brackfield. S. C. 1990. Social influences on creativity: Evaluation,coaction, and surveillance. Creativity Research lournal. 3: 6-21

[4] Amabile. T. M.. \& Gryskiewicz. N. D. 1989. The creative environment scales: Work environmentinventory. Creativity Research lournal. 2: 231-253.

[5] Singh A.P., \&Mishra L. (2009). Role of personality, motivation, and Organizational culture in creativity among managerial personal. Journal of Indian Acadmy of Applied psychology.

[6] Barron. F. 1969. Creative person and creative process. New York: Holt. Rinehart \& Winston.Barron. F. B.. \& Harrington. D. M. 1981. Creativity, intelligence, and personality. AnnualReview of Psychology. 32: 439-476.

[7] Blau, G.J. \& Boal, K.B. (1987).Conceptualizing how job involvement and organizational commitment affect turnover and absenteeism. Academy of Management Review, 12, 288-30

[8] Bakhshi, A. \& Kumar, K. (2009) National culture and organizational citizenship behavior: Development of a scale. In Singh, S. (ed.), Organizational behavior. Global Publishing House: New Delhi.

[9] Colquitt, J.A., Canlon, D.E., Wesson, M.J, \& and Porter, ( 2001 ) Justice at the millennium : A meta-analytic review of 25 years of organizational Justice research. Journal of Applied Psychology. 86, 3, 425-455.

[10] Cropanzono, R., Bowen, D.E. \& Gilliland S.W. (2007). The management of organizational justice. Academy of Management Perspectives, November, 34-48. 
[11] Cohen, W. M.. \& Levinthal, D. A. 1990. Absorptive capacity: A new perspective on learning and innovation. Administrative Science Quarterly. 35: 128- 152.

[12] Cummings. L. L. 1965. Organizational climates for creativity. Academy of Management lournal.3: 220-227.Cummings. L. L.. \& O'Connell. M. J. 1978. Organizational innovation. Iournal of Business Research. 6: 33-50.Damanpour. F. 1991. Organizational innovation: A meta-analysis of effects of determinants and moderators. Academy of Management Journal. 34: 555-590.

[13] Guilford, J. P. 1977. Way beyond the IQ: Guide to improving intelligence and creativity.Buffalo. NY: Creative Education Foundation.

[14] Guilford, J. P. 1983. Transformation abilities or functions. Journal of Creative Behavior. 17: 75-83.

[15] Greenberg, J. (1986). Behavior in organization : Understanding and managing the human side of work. Edifies. New Jersey : Prentice Hall.

[16] Greenberg, J. \& Cropanzono, R. (2001). Advance in organizational justice Standford, CA: standford University Press.

[17] Gupta, S.P., Sharma, K.D., \& Rahman A. (1971). Scientists and their commitment to organizational goals. Economic and Political Weekly, Dec 4, 2447-2450.

[18] Meyer, J.P., \& Allen, N.J., (1997). Commitment in the workplace: Theory, Research and Application. Thousand Oaks: Sage Publications.

[19] Meyer, J.P. \& Allen N.J., (1991.) A three-component conceptualization of organizational commitment. Human Resource Management Review,1, 61-89.

[20] Mathieu, J. E., \& Zajac, D. M. 1990. A review and meta-analysis of the antecedents, correlates, and consequences of organizational commitment. Psychology Bulletin, 108: 171-194.

[21] Mowday, R. T., Porter, L. W., \& Steers, R. M. 1982. Employee-organization linkages: The psychology of commitment, absenteeism, and turnover. New York: Academy Press.

[22] Sharma, B.R., \& Singh, S. (1991). Organizational commitment among Indian managers. NIPM Research Series I. New Delhi: Wiley Eastern Ltd commitment. Journal of Vocational Behavior, 14: 224-247.

[23] Sharma J.P., \& Bajpai N. (2010). Organizational commitment and its impact on job satisfaction of employees: A comparative stu dy in public and private sector in India. Gwalior: Journal of Business Administration.

[24] Morman, R.H. (1991). Relationship between organizational justice and organizational citizenship behavior: Do fairness perception influence employees citizenship behavior? Journal of applied psychology, 76: 845-855.

[25] Einstiene, R, Armeli, S. (2007) an appraisal for determinants of organizational creativity and impacts on innovative behavior. Journal of personality and social psychology, 72, 652-663.

[26] Aggrawal, Y. P. \& Verma, L.K. (1997). Internal and external control of high creative and low creative high school students at different levels of socio- economic status. Journal of creative behavior.11, 150.

[27] Jain, S., Jain, R., \& Dhar, U.(2004). Internality as a correlate of managerial creativity in indian organization. Indian journal of Industrial relations, 39(3), 324-335. 